\title{
Pneumatosis cystoides intestinalis: a case report and literature review
}

\author{
Fangmei Ling, Di Guo and Liangru Zhu* (D)
}

\begin{abstract}
Background: Pneumatosis cystoides intestinalis (PCl) is a low-incidence disease that confuses many doctors. A vast number of factors are suspected to contribute to its pathogenesis, such as Crohn's disease, intestinal stenosis, ulcerative colitis, drug use, extra-gastrointestinal diseases, and chronic obstructive pulmonary disease. Most consider its pathogenesis interrelated to an increase in intra-intestinal pressure and the accumulation of gas produced by aerogenic bacteria, and patients with atypical symptoms and imaging manifestations tend to be misdiagnosed.

Case presentation: A 64-year-old man complained of a 3-month history of bloody stool without mucopurulent discharge, abdominal pain, or diarrhea. Colonoscopy revealed multiple nodular projections into the segmental mucosa of the sigmoid colon. Crohn's disease and malignant disease ware suspected first according to the patient's history, but laboratory examinations did not confirm either. Endoscopic ultrasound (EUS) revealed multiple cystic lesions in the submucosa. Moreover, computer tomography scan showed multiple bubble-like cysts. Combined with ultrasonography, computed tomography, and pathology findings, we ultimately made a diagnosis of $\mathrm{PCl}$. Instead of surgery, we recommended conservative treatment consisting of endoscopy and oral drug administration. His symptoms improved with drug therapy after discharge, and no recurrence was noted on follow-up.

Conclusions: The incidence of $\mathrm{PCl}$ is low. Due to a lack of specificity in clinical manifestations and endoscopic findings, it often misdiagnosed as intestinal polyps, tumors, inflammatory bowel disease, or other conditions. Colonoscopy, computed tomography, and ultrasonography have demonstrated benefit in patients with multiple nodular projections in colon. Compared to the treatment of the above diseases, PCl treatment is effective and convenient, and the prognosis is optimistic. Therefore, clinicians should increase their awareness of PCl to avoid unnecessary misdiagnosis.
\end{abstract}

Keywords: Pneumatosis cystoides intestinalis, Differential diagnosis, Treatment

\section{Background}

Pneumatosis cystoides intestinalis (PCI) was first reported by Du Vernoi in 1730 [1]. In a systematic review and analysis of 239 patients with PCI, Wu et al. reported that the peak age at onset was $45.3 \pm 15.6$ years (range, 2-81 years), the male to female ratio was $2.4: 1$, and the mean disease course was 6 months [2]. After examining 123 patients with PCI, Boerner reported an equal incidence in male and female patients and that remission was achieved in $70 \%$ of patients using nonsurgical treatment [3].

\footnotetext{
* Correspondence: zhuliangru@hust.edu.cn

Division of Gastroenterology, Union Hospital, Tongji Medical College,

Huazhong University of Science and Technology, No.1277, Jiefang Avenue,

Wuhan, Hubei province, China
}

PCI is distributed throughout the digestive tract, particularly the subserous or submucosa of the small intestine and colon, in which multiple pneumocysts develop. The distal stump of the transverse splenic flexure colon, particularly the descending and sigmoid colon, is most commonly affected [2].

\section{Case presentation}

A 64-year-old man presented to the gastroenterology inpatient department with bloody stool in August 2017. There was no obvious cause of bloody stool before the patient was admitted to the hospital 3 months prior with mucus and blood attached to formed stools. The patient had no clear symptoms of abdominal pain, abdominal distension, tenesmus, fever, or night sweats. His weight had decreased by about $9 \mathrm{~kg}$ since he first became ill. $\mathrm{He}$ 
had a 5-year history of diabetes that was controlled by acarbose. A physical examination revealed no abnormalities. Laboratory investigations revealed no abnormalities except platelets count of $95 \mathrm{G} / \mathrm{L}$. Colonoscopy revealed multiple nodular projections in the segmental mucosa of the sigmoid colon, some of which were transparent (Fig. 1a). Endoscopic ultrasound (EUS) revealed multiple cystic lesions in the submucosa, followed by ringing artifacts (Fig. 1b). We suspected that the patient had pneumatosis intestinalis based on the EUS findings.

We performed further examinations to confirm the diagnosis. Intestinal computed tomography (CT) scan showed intramural gas in the sigmoid colon only (Fig. 1c, $\mathrm{d}, \mathrm{e})$. Consequently, the diagnosis of PCI was gradually established. To obtain better management, we used forceps to break the sac wall to exhaust the gas. The white bulge of the submucosa resembled a bubble after we used a snare to resect the surface of the mucosa with high-frequency electroscission (Fig. 2a, b, c). After being punctured by needles, the bubbles collapsed and the mucosa was removed and sent for pathological examination (Fig. 2d). Chronic mucosal inflammation was noted (Fig. 2e). The patient's symptoms resolved, and he was cured 3 months later after administering intestinal flora microecological therapy and other conservative medical treatments (Fig. 2f). In addition to administering 5aminosalicylic acid, we recommended that the patient discontinue the use of alpha-glucosidase inhibitor $(\alpha-\mathrm{GI})$ in the follow-up. No recurrence of digestive tract symptoms or other discomfort occurred during the 1 year of follow-up.
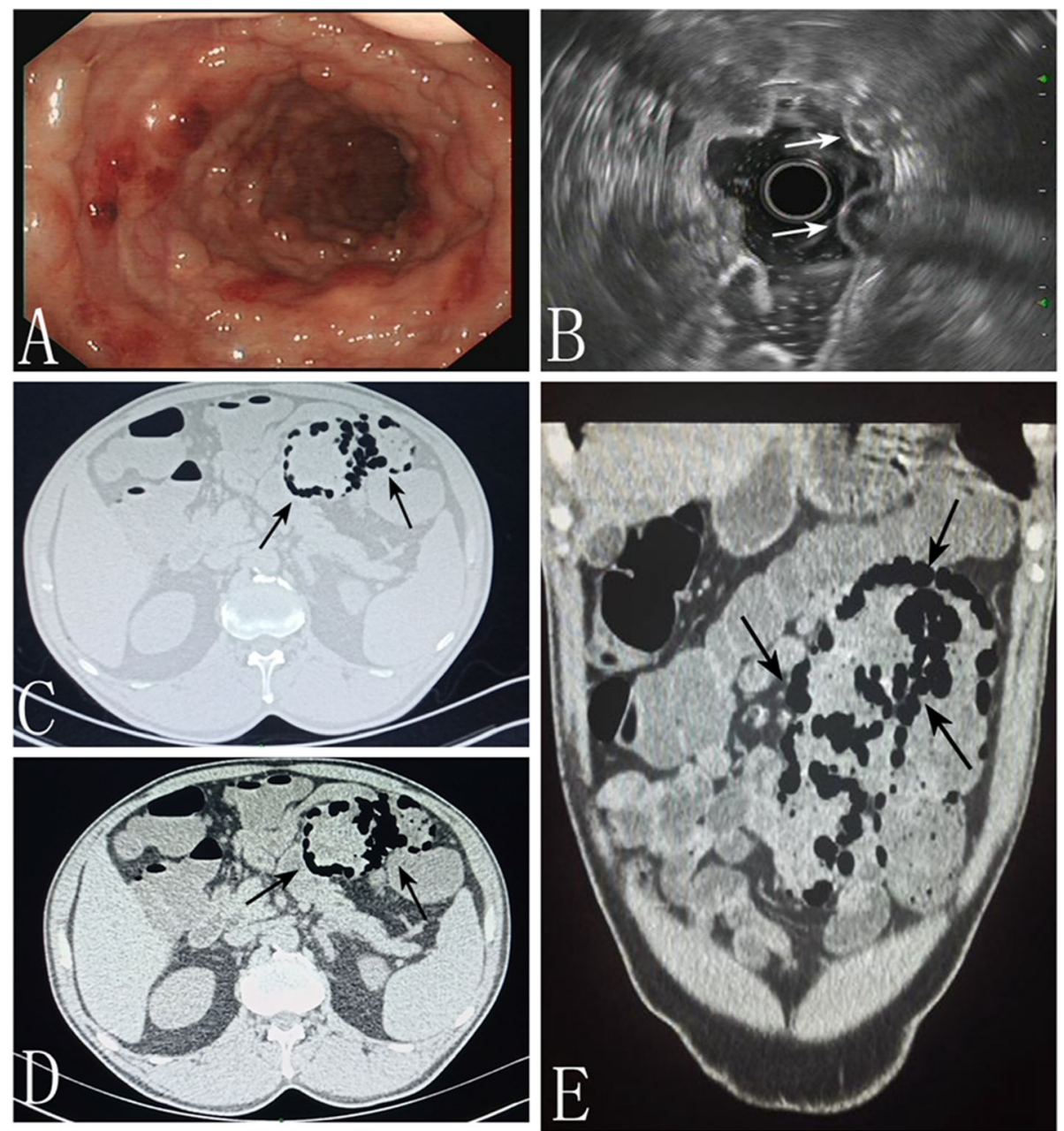

Fig. 1 Endoscopic and CT examination. a Colonoscopy disclosed multiple nodular lesions in the transverse colon and sigmoid colon. b Endoscopic ultrasonography showed hypoechoic lesions (white allows). c CT Horizontal scan. Image adjusted to lung window (black allows). d CT Horizontal scan. Image adjusted to abdominal window (black allows). e CT Vertical scan. Multiple grape-like gases were visible in sigmoid colon ((black allows) 


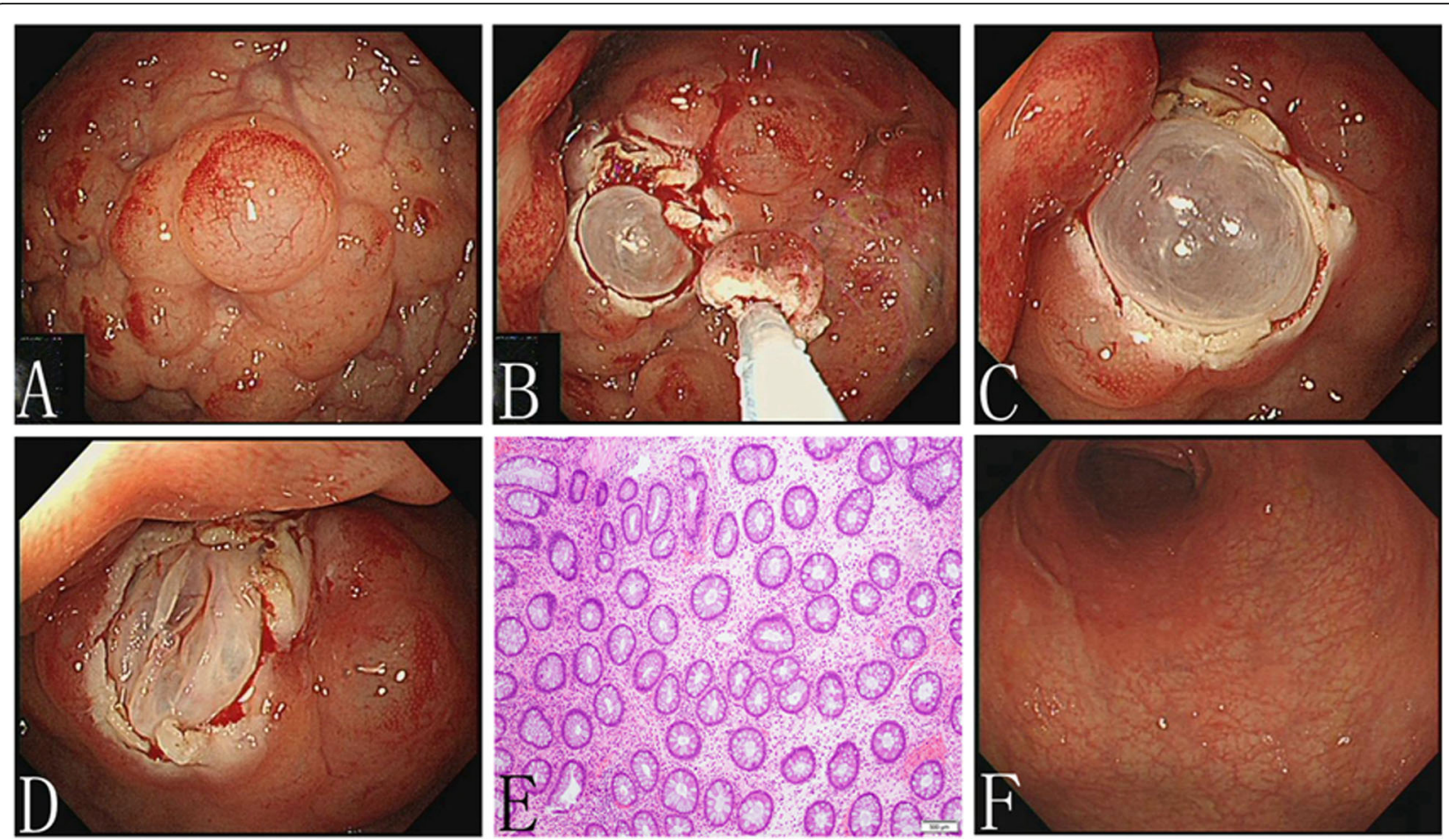

Fig. 2 Imaging and pathological features. a Cystic nodules were seen, with mucosal hyperemia and erosion. b Image after mucosal surface resection. $\mathbf{c}$ White bubble-like lesions of submucosa were seen. $\mathbf{d}$ Cyst collapse after fine needle puncture. e Pathology revealed chronic inflammation. $\mathbf{f}$ Colonoscopy showed that the surface of the mucosa was smooth

\section{Discussion and conclusions}

PCI can be divided into primary (15\%) and secondary (85\%) types $[2,4]$. The secondary type occurs secondary to diseases such as digestive tract stenosis, obstructive pulmonary disease, abdominal external injury or surgery, and malnutrition $[2,3]$. There are three hypotheses of PCI pathogenesis: (1) mechanical theory: involving an increase in intraluminal pressure that causes mechanical damage and mucosal rupture of the intestinal wall, leading to the migration of gas from the gastrointestinal cavity to the intestinal wall [1]; (2) pulmonary theory: chronic lung diseases such as chronic obstructive pulmonary disease, asthma, and interstitial pneumonia lead to alveolar rupture, causing mediastinal emphysema and release of gas along the aorta and mesenteric blood vessels into the intestinal wall [5]; and (3) bacterial theory: aerogenic bacteria penetrate the intestinal mucosal barrier, ferment in the intestinal wall, and produce gas [6].

In the present case, the patient was taking an alphaglucosidase inhibitor $(\alpha-\mathrm{GI})$ to control blood glucose. Some scholars reported that $\alpha$-GI use was associated with the pathogenesis of PCI [7, 8]; $\alpha$-GIs suppress the absorption of carbohydrates by inhibiting $\alpha-G I$ activity. Carbon dioxide, hydrogen, methane, and other metabolites are produced by the fermentation of carbohydrates. Meanwhile, pneumocysts are formed due to increased intraluminal pressure, which is attributed to peristaltic hypofunction associated with diabetes mellitus and gasproducing bacteria breaking through the mucosal integrity and invading the mucosa. Patients improve with conservative treatment, such as fasting, fluid replacement, and discontinuation of $\alpha$-GIs. Since about $30 \%$ of Japanese diabetic patients use $\alpha$-GIs, recent reports on the relationship between $\alpha$-GIs and PCI have been published primarily in Japan [7]. Kojima reported a case of PCI associated with miglitol [9]. However, whether the etiology of $\mathrm{PCI}$ is related to $\alpha$-GIs requires further exploration. Therefore, in clinical practice, when patients with diabetes complain of gastrointestinal symptoms, the possibility of PCI should be considered.

PCI lesions are mainly located in the colon $(46 \%)$ and small intestine $(27 \%)$, followed by the large and small intestine (7\%) and stomach (5\%) [10]. The clinical manifestations of primary PCI are nonspecific, such as abdominal pain (59\%), diarrhea (53\%), nausea and vomiting (14\%), mucus in stool (12\%), and hematochezia (12\%) [2]. Secondary PCI also has primary disease manifestations. About 3\% of the patients with PCI complained of complications, including pneumoperitoneum, volvulus, intestinal obstruction, and intestinal ischemia $[1,2,11-13]$. Serious complications may alter the decision-making process for the therapeutic schedule.

The laboratory examination and pathological biopsy of PCI are nonspecific; the diagnosis mainly depends on 
colonoscopy, CT, radiography, and ultrasound findings. However, it is easily confused with intestinal polyps [14], cancer [15], or inflammatory bowel disease [16], necrotising enterocolitis [17], even if colonoscopy and biopsy are performed due to a lack of awareness of PCI. Many cases can be found in clinical practice in which patients with pneumoperitoneum signs were initially misdiagnosed as having digestive tract perforation and suffered from unnecessary surgery [18-20].

Some researchers reported that the abdominal CT characteristics of PCI are multiple submucosal or subserosal cystic transmission areas that resemble a bunch of grapes [12]. Furthermore, CT images taken at different levels enable estimation of lesion location and extent through three-dimensional scanning. The image can be observed more clearly when adjusted to the lung window. The discovery of the presence of gas in the portal vein is one of the advantages of $\mathrm{CT}$ examination, which is particularly important for making therapeutic decisions. Lassandro et al. found that gas in the portal vein was present in approximately $25.5 \%$ of PCI patients. In these patients, the incidence of intestinal obstruction increased and the mortality rate increased to 50\% [21]. EUS has high diagnostic value in PCI: multiple cystic lesions without echoes are visible at the sigmoid colon with rear ringing artifacts. EUS provides reliable imaging evidence for making a definitive diagnosis. Ribaldone et al. mentioned that EUS is effective for analyzing the nature and source of intestinal masses, which is a unique advantage [22].

Although the diagnosis of PCI mainly depends on medical imaging, biopsy is still highly recommended. First, the endoscopic manifestations of PCI patients usually present as polypoid or protuberant lesions. With the development of industrialized countries in the twentyfirst century, the incidence of Crohn's disease and colon cancer has continually increased and concomitantly, the number of colonoscopy examinations [23, 24]. The symptoms, location, and endoscopic manifestations of PCI are also similar to those of other diseases, such as inflammatory bowel disease, intestinal neoplasms, and intestinal polyps [14-16]. Additionally, PCI has been associated with Crohn's disease and both can coexist in the same patient [25]. Moreover, the specific etiology of Crohn's disease combined with PCI is unclear, which may be a result of the surgical history of Crohn's disease patients [26]. A pathological biopsy cannot be neglected in this situation and can be conducive for accurate and systematic analysis. Pathological findings of giant cell arrays and partial or collapsed cysts may be helpful in differentiating PCI [27]. Therefore, increasing the doctor's understanding of PCI is imperative for proper management. Making correct judgments on PCI avoids increasing the psychological and economic burden on patients and unnecessary medical procedures, such as mucosal dissection and surgery, especially by doctors in grassroots units, whose clinical experience is relatively lacking.

If a PCI is suspected, CT examination and ultrasound endoscopy should be performed when conditions permit, and the factors causing PCI should be explored. In addition to gastrointestinal diseases and emphysema, some rare events are associated to PCI, such as alphaglucosidase inhibitors [7], sunitinib [20], lung transplantation [28], bone marrow transplantation [29], systemic lupus erythematosus [30], systemic sclerosis [11], myeloma [31], granulomatosis with polyangiitis [32]. Moreover, the mucosal damage caused by colonoscopy and biopsy may result in the gas entering the intestinal mucosa, thereby promoting the occurrence of PCI [33]. Therefore, it is not enough to reach a superficial diagnosis, as more examination are necessary to investigate the disease etiology. In our case, the cause of PCI could be related to the use of $\alpha$-GI. It is worth mentioning that in 2019 we re-enrolled a patient with PCI who also had a history of taking acarbose, who is currently undergoing treatment. For patients with PCI, we should investigate their medical history as far as possible, inquring about the recent use of alpha-glucosidase inhibitor, multityrosine kinase inhibitor, glucocorticoid, and other drugs, exploring whether there is a combination of lung diseases, gastrointestinal diseases, diabetes, autoimmune diseases, cancer history, and organ transplantation history. At the same time, combined with medical history is beneficial to pertinently screen the pathogeny and eliminate potential influencing factors, such as mucosal damage, increased intestinal pressure, and bacterial infection. A thorough assessment of the clinical background of PCI and the correct comprehension of the differential diagnosis of $\mathrm{PCI}$ is essential to avoid unnecessary surgery.

Most researchers believe that PCI is a benign disease with conservative treatments: (1) observation; (2) oxygen or hyperbaric oxygen therapy. Kensuke Nakatani et al. reported that hyperbaric oxygen therapy is the preferred method [32]; (3) antibiotics including metronidazole and quinolones can inhibit intestinal bacterial infection; and (4) endoscopic treatment. Endoscopic fine needle aspiration contributes to the diagnosis and treatment of PCI, by puncturing the cyst to exhaust gas [34-37]. PCIinduced intestinal obstruction can be treated by the high-freguency endoscopic resection of the cyst wall, and cyst collapse after gas discharge [36]. Because the presence of multiple sites of operations and biopsies increase the risk of infection by nearly 9 times, local implementations are generally recommended [36, 37]. However, some patients developed intestinal obstruction again after relieving the first obstruction. At this point, 
sclerotherapy of the cyst wall after puncture may be a solution to prevent the cyst from expanding again [18].

Surgical intervention is not absolutely necessary to treat PCI. How accurately identifying the timing of surgery has become a clinical challenge. Generally speaking, the prognosis of PCI is good, and the poor predictors of prognosis include $\mathrm{pH}$ value $<7.3$, bicarbonate level $<20 \mathrm{ml} / \mathrm{L}$, lactate level $>2 \mathrm{mmol} / \mathrm{L}$, amylase level $>200 \mathrm{U} / \mathrm{L}$, and presence of portal venous gas $[4,11,13,38]$. A level of $>2 \mathrm{mmol} / \mathrm{l}$ of lactate was the strongest predictor of pathological PCI and correlated with adverse outcomes [13]. In order to more rapidly identify and manage patients with severe PCI, patients should be divided into three groups: patients requiring surgery, patients with invalid surgery, and patients with benign intestinal emphysema. The primary operative indications are considered if the patient meets any of the following criteria: obstructive symptoms, WBC $>12 \mathrm{c} /$ $\mathrm{mm}^{3}$ or CT findings of portal vein gas, especially when the patient is older than 60 years old, due to the high mortality rate associated with this condition. For secondary indications, if patients have sepsis or signs of acidosis $(\mathrm{pH}<7.3$, lactate $>2.0$, bicarbonate $<20)$, surgery should be performed [4]. Patients with acute abdomen, acute kidney injury, or hypotension can also be treated surgically [38]. Accordingly, PCI patients should undergo detailed physical examination and as well as renal function and blood-gas analysis, CT, and tests for amylase and Creactive protein levels, along with other tests, so as to quickly identify patients who need surgery and patients who can be relieved by conservative treatment. Although lactic acid was not detected in our case, the patient was evaluated for benign PCI from abdominal signs, white blood cells, blood pressure, and CT. Therefore, nonsurgical treatments to eliminate cysts were selected. PCI is relatively unfamiliar to inexperienced clinicians, and an optimal PCI management model has yet to be suggested.

To conclude, PCI is a not uncommon disease with male predominance and unclear etiology and pathogenesis. Because abdominal pain, diarrhea, and other nonspecific abdominal symptoms are the main clinical manifestations, it is easily confused with intestinal polyps, cancer, or inflammatory bowel disease. With increase in the number of endoscopies, it is essential to improve the doctor's comprehension of PCI. The diagnosis mainly depends on abdominal CT and colonoscopy findings. For example, CT shows a number of grape-like or beaded low-density cystic light transmission areas. Treatment includes observation, oxygen therapy, endoscopic treatment, and surgery. The treatment should be tailored to the clinical symptoms and endoscopic manifestations to avoid unnecessary surgery. If no serious complications occur, the prognosis is optimistic.

\section{Acknowledgements}

We sincerely thank the department of pathology and radiology in our hospital for providing information.
Authors' contributions

FL wrote the manuscript and acquired information of the patient. DG performed literature review and followed-up. LZ revised the manuscript. All authors have read and approved the final manuscript.

\section{Funding}

This case report was not supported by relevant funds.

\section{Availability of data and materials}

All information about the patient come from department of

Gastroenterology, Wuhan Union Hospital. The data used and analyzed during the current study are included in this article.

Ethics approval and consent to participate

Not applicable

\section{Consent for publication}

We have obtained the patient's consent and signed the patient consent. A copy of the written consent is available for review from the Editor-in-Chief of this journal.

\section{Competing interests}

The authors declare that they have no competing interests. All authors have confirmed that no support from any organization for the submitted work; no financial relationships with any organization that might have an interest in the submitted work in the previous 3 years, no other relationships or activities that could appear to have influenced the submitted work.

Received: 5 March 2019 Accepted: 2 October 2019

Published online: 06 November 2019

\section{References}

1. Khail PN, Huber-Wagner S, Ladurner R, Kleespies A, Siebeck M, Mutschler W, Halfeldt K, Kanz KG. Natural history, clinical pattern, and surgical consideration of pneumatosis interstialis. Eur J Med Res. 2009;14(6):231-9.

2. Wu L-L, Yang Y-S, Dou Y, Liu Q-S. A systemic analysis of pneumatosis cystoids intestinalis. World J Gastroenterol. 2013;19(August (30)):4973-8.

3. Boerner RM, Frie DB, Warshauer DM, Isaacs K. Pneumatosis intestinalis. Two case reports and a retrospective review of literature from 1985 to 1995. Dig Dis Sci. 1996;41(11):2272-85.

4. Greenstein AJ, Nguyen SQ, Berlin A, Corona J, Lee J, Wong E, Factor SH, Divino CM. Pneumatosis intestinalis in adults: managements, surgical indivations, and risk factors for mortality. J Gastrointest Surg. 2007;11(10):1268-74.

5. Keyting WS, McCarver RR, Kovarik JL, Daywitt AL. Pneumatosis intestinalis: a new concept. Radiology. 1961;76:733-41.

6. Gillon J, Tadesse K, Logan RF, Holt S, Sircus W. Breath hydrogen in pneumatosis cystoides intestinalis. Gut. 1979;20:1008-11.

7. Tsujimoto T, Shioyama E, Moriya K. Pneumatosis cystoides intestinalis following alpha-glucosidase inhibitor treatment: a case report and review of the literature. World J Gastroenterol. 2008;14(39):6087-92.

8. Hayakawa T, Yoneshima M, Abe T, Nomura G. Pneumatosis cystoides intestinalis after treatment with an alpha-glucosidase inhibitor. Diabetes Care. 1999:22:366-7.

9. Kojima K, Tsujimoto T, Fujii H, Morimoto T, Yoshioka S, Kato S, Yasuhara Y, Aizawa S, Sawai M, Makutani S, Yamamoto K, Mochi T, Fukui H. Pneumatosis cystoides intestinalis induced by the a-glucosidase inhibitor miglitol. Intern Med. 2010;49(15):1545-8.

10. Morris MS, Gee AC, Cho SD, Limbaugh K, Underwood S, Ham B, Schreiber MA. Management and outcome of pneumatosis intestinalis. Am J Surg. 2008;195(5):679-82.

11. Kanchela D, Vattikuti S, Vipperla K. Pnematosis cystoides intestinalis: is surgery always indicated? Cleve Clin J Med. 2015;82(3):151-2.

12. Ogul H, Pirimoglu B, Kisaoglu A, Karaca L, Havan N, Ozogul B, Kantarci M. Pneumatosis cystoides intestinalis: an unusual cause of intestinal ischemia and pneumoperitoneum. Int Surg. 2015;100(2):221-4.

13. DuBose JJ, Lissauer M, Maung AA, Piper GL, O'Callaghan TA, Luo-Owen X, Inaba K, Okoye O, Shestopalov A, Fielder WD, Ferrada P, Wilson A, Channel J, Moore FO, Paul DB, Johnson S. Pneumatosis intestinalis predictive evaluation study (PIPES):a multicenter epidemiologic study of the eastern association for the surgery of trauma. J Trauma Acute Care Surg. 2013;75(1):15-23. 
14. Ponz de Leon M, Bertarelli C, Casadei GP, Grilli A, Bacchini P, Pedroni M, Jovine E. A case of pneumatosis cystoides intestinalis mimicking familial adenomatous polyposis. Familial Cancer. 2013;12(3):573-6.

15. Liu T, Zhang S, Mao H. Gastrointestinal malignant neoplasms disguised as pneumatosis cystoids intestinalis: a case report and literature review. Medicine (Baltimore). 2017;96(51):e9410.

16. Suarez V, Chesner IM, Price AB, Newman J. Pneumatosis cystoides intestinalis. Histological mucosal changes mimicking inflammatory bowel disease. Arch Pathol Lab Med. 1989;113(8):898-901.

17. Ang CH, Li XF, Ong LY, Low Y. Pneumatosis Intestinalis in meconium inspissation mimicking Necrotising Enterocolitis. Indian J Pediatr. 2017;84(4):328-9.

18. Johansson $\mathrm{K}$, Lindström $\mathrm{E}$. Treatment of obstructive pneumatosis coli with endoscopic sclerotherapy: report of a case. Dis Colon Rectum. 1991;34(1):94-6.

19. Dhadie S, Mehanna D, McCourtney J. Pneumatosis intestinalis a trap for the unway: case series and literature review. Int J Surg Case Rep. 2018;53:214-7.

20. Lee YS, Han JJ, Kim SY, Maeng CH. Pneumatosis cystoides intestinalis associated with sunitinib and a literature review. BMC Cancer. 2017;17(1):732

21. Lassandro F, Mangoni de Santo Stefano ML, Porto AM, Grassi R, Scaglione $\mathrm{M}$, Rotondo A. Intestinal pneumatosis in adults: diagnostic and prognostic value. Emerg Radiol. 2010;17(5):361-5.

22. Ribaldone DG, Bruno M, Gaia S, Saracco GM, De Angelis C. Endoscopic ultrasound to diagnose pneumatosis cystoides intestinalis (with video). Endosc Ultrasound. 2017;6(6):416-7.

23. Kaplan GG. The global burden of IBD: from 2015 to 2025. Nat Rev Gastroenterol Hepatol. 2015;12(12):720-7.

24. Mármol I, Sánchez-de-Diego C, Pradilla Dieste A, Cerrada E, Rodriguez Yoldi $\mathrm{MJ}$. Colorectal carcinoma: a general overview and future perspective in colorectal cancer. Int J Mol Sci. 2017;18(1):197.

25. Galandiuk S, Fazio WW, Petras RE. Pneumatosis cystoides intestinalis in Crohn's disease. Report of two cases. Dis Colon Rectum. 1985;28(12):951-6.

26. Breitinger A, Kozarek R, Hauptman E. Pneumatosis cystoides intestinalis in Crohn's disease. Gastrointest Endosc. 2003;57(2):241.

27. Koreishi A, Lauwers GY, Misdraji J. Penmatosis intestinalis:a challenging biopsy diagnosis. Am J Surg Pathol. 2007;31(10):1469-75.

28. Beetz O, Kleine M, Vondran FWR, Cammann S, Klempnauer J, Kettler B. A case of recurrent pneumoperitoneum and pneumatosis intestinalis after bilateral lung transplan. Exp Clin Transplant. 2019:17(1):124-7.

29. Day DL, Ramsay NK, Letourneau JG. Pneumatosis intestinalis after bone marrow transplantation. AJR Am J Roentgenol. 1988;151(1):85-7.

30. Marinello DK, Rafael D, Paiva Edos S, Dominoni RL. Systemic lupus erythematosus complicated by intestinal vasculitis and pneumatosis intestinalis. Rev Bras Reumatol. 2010:50:596-602.

31. Raghunathan V, Louis D, Wirk B. Gastrointestinal tract amyloidosis presenting with pneumatosis intestinalis. J Clin Med Res. 2017;9(7):654-8.

32. Nakatani K, Kato T, Okada S, Matsumoto R, Nishida K, Komuro H, Suganuma T. Successful treatment with hyperbaric oxygen therapy for pneumatosis cystoides intestinalis as a complication of granulomatosis with polyangiitis: a case report. J Med Case Rep. 2017;11:263.

33. Deer M, Altorfer J, Pirovino M, Schmid M. Pneumatosis cystoides coli: a rare complication of colonoscopy. Endoscopy. 1983;15:119-20.

34. Cyrany J, Kopácová M, Rejchrt S, Hornychová H, Tomsová M, Tycová V, Ryska A, Bures J. Puncture and cytology - sufficient for endoscopic diagnosis of pneumatosis cystoides intestinalis? Endoscopy. 2009:41(Suppl 2):E127-8.

35. Takahashi K, Fujiya M, Ueno N, Ando K, Kashima S, Moriichi K, Okumura T. Endoscopic fine-needle aspiration is useful for the treatment of pneumatosis cystoides intestinalis with intussusception. Am J Gastroenterol. 2019;1 14(1):13.

36. Wang YJ, Wang YM, Zheng YM, Jiang HQ, Zhang J. Pneumatosis cystoides intestinalis: six case reports and a review of the literature. BMC Gastroenterol. 2018;18(1):100

37. Kim YG, Kim KJ, Noh SH, Yang DH, Jung KW, Ye BD, Byeon JS, Myung SJ, Yang SK Clear water filling and puncture: sufficient for endoscopic diagnosis of pneumatosis cystoides intestinalis? (with video). Gastrointest Endosc. 2011;74(5):1170-1.

38. Tahiri M, Levy J, Alzaid S, Anderson D. An approach to pneumatosis intestinalis: Factors affecting your management. Int I Surg Case Rep. 2015:6:133-137.

\section{Publisher's Note}

Springer Nature remains neutral with regard to jurisdictional claims in published maps and institutional affiliations.

\section{Ready to submit your research? Choose BMC and benefit from:}

- fast, convenient online submission

- thorough peer review by experienced researchers in your field

- rapid publication on acceptance

- support for research data, including large and complex data types

- gold Open Access which fosters wider collaboration and increased citations

- maximum visibility for your research: over $100 \mathrm{M}$ website views per year

At BMC, research is always in progress.

Learn more biomedcentral.com/submissions 